\title{
COMMUNICATION ABILITIES TO UNDER GRADUATE LEVEL IN TELANGANA FOR BOOSTING EXPLOITABILITY
}

\author{
DR. M. RAJITHA
}

Lecturer, Department of English, GDC, Nirmal, Telangana, India

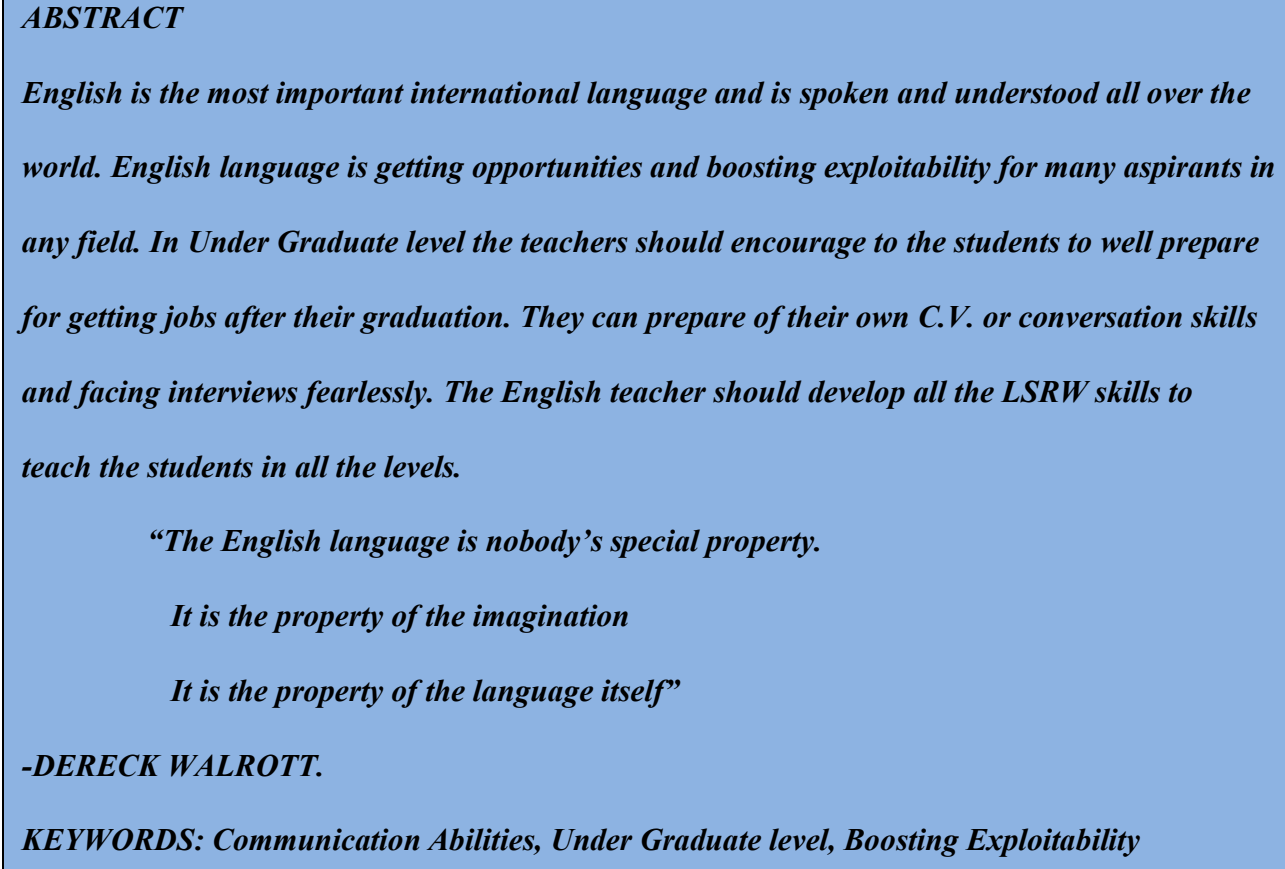

Received: Jan 09, 2021; Accepted: Jan 29, 2021; Published: Feb 13, 2021; Paper Id.: IJELFEB20214

\section{INTRODUCTION}

This paper focuses on how to improve communication abilities to under graduate students in Telangana for exalting exploitability with effective skills and complete with all dimensions.

Enhancing language skills in English can result to better job opportunities in the Professional world. Nowadays importance of English in employability and in career development is very essential. Having good communication abilities can create wonderful opportunities for everyone. English is the most important used language universally.

\section{ROLE OF COMMUNICATION ABILITIES IN GETTING EXPLOITABILITY}

It is completely true that communication skills tops the list of employability parameters and plays a crucial role in all the fields. Communication abilities are ultimately accustomed in this function world.

\section{TRANSMISSION IN ENGLISH}

Communication exposes in two directions. One is verbal and other one is non-verbal. 
Communication reciprocates in words and sounds. This is called verbal communication. And information transforms into signals eye gaze, attitude and visual communication is called non verbal communication. Verbal communication constitutes vocal and written transmission. Vocal transmission skills incorporate the abilities to state efficaciously and listen energetic and answer successfully as claimed by the circumstances. It is helps to the Under Graduate students to facing interviews, attending meetings, lectures, phone conversations, video conferences.

Communicative abilities would entirely giving best chances to the Under Graduate students.

Learning most of the languages can stand the business world.

There are 1160 degree colleges including 169 colleges in Hyderabad. Of 1160 colleges in Telangana, only 135 are accredited by NAAC. National Institutional Ranking Framework (NIRF) by MHRD not a single college from Telangana made it to the list of top -100 colleges. Compared to this Tamil Nadu had 38 colleges in the list, Kerala had 17, Karnataka and Andhra Pradesh had three and two colleges respectively.

\section{FOCUS NEEDED ON QUALITY}

English language skills and employability are interrelated in any field in the world. So many courses are designed to teach English as a skill. So as to enhance this English language competencies along with their technical or professional improvement. A good language lab should provide the students to enhance their communication skills also. But in Under Graduate level students faces so many problems. Because they need to good learning labs in their colleges.

So many degree colleges no infrastructure for better learning. The government should provide these facilities for better learning and employability. These skills are helpful to the students to cracking their interviews. Experts are of the opinion that getting down the number of seats in private degree colleges will improve quality of education. In my opinion working as a lecturer in government degree college, as I am observing from 2009 to till now there is unhealthy competition in filling up degree admissions. Most of the students prefer to join in Engineering and diploma courses past few years. So this is the main reason to merge so many degree colleges in Telangana. Every year of the 4, 07 lakh seats available in about all degree colleges those were part of degree online services in Telangana. For admissions, almost 2.10 lakh seats went vacant even after four phases of counselling. Lack of strict quality control measures in degree colleges by universities which provide affiliated like O.U., K.U. and M.G.U. is a major drawback. As per collegiate education there are about 274 courses available in degree colleges across the state.

\section{INTEGRATION OF INFORMATION AND COMMUNICATION}

\section{TECHNOLOGIES FOR TEACHING AND LEARNING}

- $\quad$ E- Governance / E- Office

- $\quad$ E-Content / MOOCS

- National Academic Depository (NAD)

- Annual Refresher Program in Teaching (ARPIT)

- Skill Development Initiatives UGC skill development schemes (NSQF )

- Open Distance and Online Learning 
- Open distance education program

- Online learning

These are all above programs conducted by UGC (MHRD) government of India.

This Programs specially conducted for higher education students and faculty to improve their communication and language skills for better employability.

The students' enrolment in terms of percentage at various levels was $79.76 \%$ at U.G. level.

Gross enrolment Ratio (GER) in Higher Education in India is 26.3\% which is calculated for 18-23 years of age group. GER foe male population is $26.3 \%$ and for Female it is $26.4 \%$.

During the academic session 2018-19 the total students enrolment in all courses and levels in regular and distance education programs was 373.99 lakh including 181.90 lakhs women students constituting 48.64\%. The maximum number of students had been enrolled in the state of U.P. (64.69 lakhs), followed by Maharashtra (42.30 lakhs), Tamil Nadu (34.14 lakhs) and W.B. (20.97).

\section{CONCLUSIONS}

As we know, English is the ultimately unique language which is connects people from different regions, cultures, nations and religions in the business world. Communication means the reciprocate of facts, plans, tenderness and concepts. It is the development of Under Graduate level awaits that will great wary. This language skills needs to the Under Graduate students to Listening, Speaking, Reading and Writing, (LSRW) abilities to communicate English well, verbally and Nonverbally. It is also helpful to the Under Graduate students to solving problems, critical thinking, time managing etc. life skills will reach the goal. Creating employable skilled Under Graduate students to getting Government jobs Group-I, Group-II, Banking etc government jobs in Telangana. Most of the people from rural areas and urban areas are also perfect in regional language as well as fruitful in their business field. So, communicative abilities plays a vital role in getting good exploitability for Under Graduate level.

\section{REFERENCES}

1. Ramakantha Sharma: Importance of communication.

2. Mudassir Khan, "The Scope of E-Learning in the Computer Science \& Technologies “, International Journal of Computer Science Engineering and Information Technology Research (IJCSEITR), Vol. 6, Issue 6, pp. 1-6

3. Alok Kumar, Vikash Pawariya \& Ravindra Singh, "Managerial Ability of Lime Growers About Recommended Cultivation of Lime In Rajasthan “, International Journal of Agricultural Science and Research (IJASR), Vol. 7, Issue 2, pp. 155-162

4. http:// www.languageindia.com

5. Faculty focus special report: Effective strategy for improving college teaching and learning. Rhines Cheney, Gretchen et al.2005.

6. Varsha Saini \& Bimla Dhanda, "A Complementary Relationship between Communication Skills and Social Skills among Rural Children “, International Journal of Humanities and Social Sciences (IJHSS), Vol. 6, Issue 2,pp. 11-16

7. Annual Report 2018-19, Department of Elementary Education and Literacy \& Department of Secondary and Higher Education, Ministry Of Human Resource Development, Government of India. 
8. www.researchgate.net.

9. Aditi Jain \& Shivani Lal, "Factors Retarding the Efficacy of Nursing Communication In Hospitals and Strategies to Overcome Them “, BEST: International Journal of Humanities, Arts, Medicine and Sciences (BEST: IJHAMS) , Vol. 3, Issue 12, pp. $1-12$

10. www.deccanherald.com

11. http:// www.employment news. Gov. in/ career-IN-ENGLISH-LANGUAGE-TRAINING.asp

12. www.wordsworthelt.com/blog/empolability-english...

13. Basic English language skills- Oxbridge Academy. 